02

\title{
Комбинационное рассеяние света в хирально чистых и рацемической фазах поликристаллов триптофана и тирозина
}

\author{
(ㄱ В.С. Горелик ${ }^{1,2}$, М.Ф. УМаров ${ }^{3}$, Ю.П. Войнов ${ }^{1}$ \\ ${ }^{1}$ Физический институт им. П.Н. Лебедева РАН, \\ 119991 Москва, Россия \\ ${ }^{2}$ МГТУ им. Н.Э. Баумана, \\ 105005 Москва, Россия \\ ${ }^{3}$ Вологодский государственный университет, \\ 160000 Вологда, Россия \\ e-mail: gorelik@sci.lebedev.ru
}

Поступила в редакцию 22.05.2019 г.

В окончательной редакции 22.05.2019 г.

Принята к публикации 04.06.2019 г.

\begin{abstract}
Выполнен анализ спектров комбинационного рассеяния (КР) света поликристаллов триптофана и тирозина в широком спектральном интервале методом волоконно-оптической спектроскопии. Регистрация спектров КР проводилась с применением спектрометра типа BWS465-785H в спектральном диапазоне $0-2700 \mathrm{~cm}^{-1}$, при использовании в качестве возбуждающего излучения непрерывного лазера с длиной волны генерации $785 \mathrm{~nm}$. Сопоставлены параметры спектров КР трех кристаллических фазовых модификаций ароматических аминокислот: левой (L); правой (D) и рацемической фаз (DL). B низкочастотных спектрах КР кристаллических решеток аминокислот триптофана и тирозина обнаружено присутствие интенсивных комбинационных спутников, характеристики которых видоизменяются в зависимости от типа хирального фазового состояния аминокислоты. Полученные результаты могут быть использованы для контроля хиральной чистоты биоактивных препаратов, содержащих аминокислоты.
\end{abstract}

Ключевые слова: комбинационное рассеяние, кристаллические аминокислоты, хиральное фазовое состояние.

DOI: $10.21883 /$ OS.2019.10.48354.162-19

\section{Введение}

Протеиногенные аминокислоты являются составляющими компонентами белков и играют важную роль в процессах жизнедеятельности биологических объектов [1]. Свойства поликристаллических аминокислот во многом определяются образованием цвиттер-ионов и существованием межмолекулярных водородных связей. Изучение спектров комбинационного рассеяния (КР) света аминокислот представляет научный интерес в связи с возможностью характеризации различных фазовых состояний биоструктур (моно- и биполярных форм, лево- и правовращающих оптических изомеров и др.). Наибольший интерес представляют спектральные исследования в низкочастотной области кристаллических аминокислот, которые дают прямую информацию о межмолекулярных взаимодействиях, играющих важную роль во многих биофизических процессах. В геноме человека кодируется 20 аминокислот, входящих в состав белков живых организмов. Наиболее эффективными люминофорами являются ароматические аминокислоты: фенилаланин, тирозин и триптофан. В связи с этим изучение спектров КР ароматических аминокислот представляется важной задачей, позволяющей установить закономерности процессов переноса энергии в белках и сложных биологических объектах. Для эффективно- го использования аминокислот необходимо обеспечение соответствия их молекулярной структуры и состава номинальным препаратам, воздействие которых на биологические структуры и живые организмы надежно установлено. В зависимости от аминокислотного остатка молекулы аминокислот могут существовать в виде двух зеркально-симметричных изомерах: L (левозакрученная форма) и D (правозакрученная спираль). Кроме того, возможно существование так называемых рацематов (DL) - фаз, в структуре которых присутствуют и „левые“ и „правые“ молекулы. Исследования колебательных спектров аминокислот неоднократно выполнялись с использованием методов спектроскопии КР [2-15] и ИК спектроскопии [16-23]. В частности, большое внимание уделялось области внутримолекулярных мод, в которой проявлялись колебательные степени свободы аминокислотных остатков, а также колебания групп $\mathrm{C}-\mathrm{H}$ и $\mathrm{N}-\mathrm{H}$.

Bсе естественные протеиногенные аминокислоты имеют L-конформацию. Аминокислоты D-конформации, как правило, живыми клетками не усваиваются. Продуктом химической реакции без участия какого-либо асимметричного агента, реагирующего на зеркальную асимметрию молекулы, является рацемическая фаза (DL-конформация) или смесь в равных концентрациях D- и L-конформаций. Присутствие в организме рацема- 
тов и правых (D) конформаций аминокислот приводит к нарушению процессов жизнедеятельности.

В связи с этим возникает задача выявления типа хирального состояния аминокислот для их практического использования при создании фармацевтических препаратов, при введении аминокислот в пищевые продукты в качестве биологически активных добавок и т.д. Для решения такой задачи могут быть использованы различные спектральные методы, включая фотолюминесценцию, КР-спектроскопию, нелинейно-оптическую спектроскопию и т. д. [24-26]. Для однозначного ответа на вопрос о степени соответствия молекулярной структуры и состава анализируемой аминокислоты, характеристики которой присутствуют в базе данных, необходимо провести на количественном уровне сравнение спектров различных модификаций анализируемых аминокислот. В настоящей работе методом КР-спектроскопии проанализированы различные хиральные состояния ароматических аминокислот: триптофана и тирозина.

\section{Методика эксперимента}

В качестве объектов исследования нами были выбраны поликристаллические образцы аминокислоты триптофана в виде L-, D- и DL-конформаций, а также Lи D-модификации поликристаллов тирозина. Образцы были предоставлены фирмой „Roanal“ (Венгрия). В таблице приведены химические и структурные формулы исследованных фаз триптофана и тирозина. Как видно из этой таблицы, в структуре обеих фаз триптофана присутствуют ароматические кольца, что приводит к фундаментальному электронному поглощению этими соединениями в среднем ультрафиолетовом диапазоне. Соответственно в этих веществах наблюдается фотолюминесценция в фиолетово-синем диапазоне при возбуждении образцов коротковолновым электромагнитным излучением [27].

Для возбуждения и регистрации спектров КР использовалась волоконно-оптическая методика [28-32]. Принципиальная схема используемой экспериментальной установки приведена на рис. 1. В качестве источника возбуждающего излучения был использован лазер 1 с длиной волны генерации $\lambda=785 \mathrm{~nm}$ и мощностью $200 \mathrm{~mW}$. Использование длинноволнового инфракрасного излучения для возбуждения спектров КР биологических объектов оправдано в связи с обеспечением неразрушающего воздействия на биологически активные молекулы анализируемой среды. Лазерное излучение вводилось в первый световод 2 и зонд 3. С помощью линзы 5 это излучение фокусировалось на образце 6 , имеющем вид поликристаллического порошка. Возникающий в образце сигнал КР попадал на второй световод 14 , фильтровался в фокусаторе 13 с помощью фотонного кристалла 9 и поступал на вход мини-спектрометра 12 с многоэлементным приемником. Компьютер 11 был предназначен для цифровой обработки и накопления

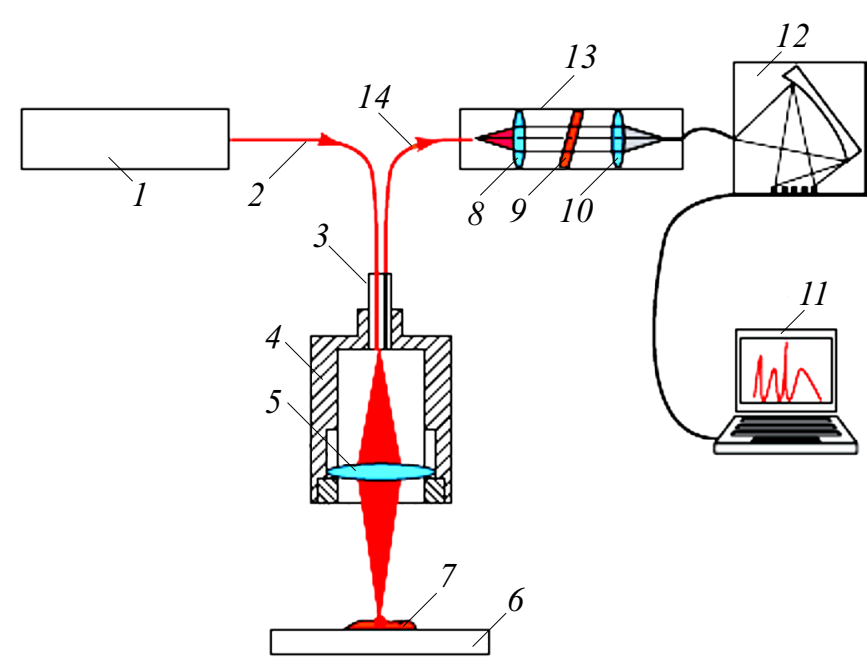

Рис. 1. Схема экспериментальной установки: 1 - лазер; 2,14 - первый и второй кварцевые световоды; 3 - зонд; 4 - корпус; 5 - линза; 6 - подложка; 7 - образец; 8,10 - линзы; 9 - фотонный кристалл; 11 - персональный компьютер; 12 - мини-спектрометр FSD0-8; 13 - фокусатор.

спектров КР. Спектральное разрешение при регистрации спектров КР составляло $1 \mathrm{~cm}^{-1}$. Используемый волоконно-оптический метод позволил регистрировать спектры КР от небольшого количества (менее $1 \mathrm{mg}$ ) поликристаллического образца с экспозицией 10-100 s. Кварцевый световод использовался для подведения лазерного излучения к веществу и для отведения вторичного излучения, возникающего в анализируемой пробе, к малогабаритному спектрометру типа BWS465-785H. При этом пространственное разрешение на поверхности анализируемой пробы составляло $\sim 0.1 \mathrm{~mm}$. Используемый спектрометр позволял осуществлять регистрацию спектра КР исследуемых веществ в диапазоне значений частоты $0-2700 \mathrm{~cm}^{-1}$. От мини-спектрометра цифровая информация о спектре КР света передавалась на компьютер. После компьютерной обработки нами были построены нормированные спектры КР триптофана и тирозина, а также построены разностные спектры КР, позволяющие устанавливать степень хиральной чистоты исследуемых образцов на количественном уровне.

\section{Результаты и их обсуждение}

Ha рис. 2 приведены спектры KP L-, D- и DL-триптофана, зарегистрированные в области решеточных и внутримолекулярных мод при комнатной температуре в широком спектральном диапазоне, включающем области решеточных $\left(0-200 \mathrm{~cm}^{-1}\right)$ и внутримолекулярных $\left(200-3000 \mathrm{~cm}^{-1}\right)$ мод. В соответствии с [33] кристалл триптофана принадлежит к пространственной группе $\mathrm{P} 22_{1} / \mathrm{c}\left(\mathrm{C}_{2 \mathrm{~h}}^{5}\right)$ с четырьмя молекулами в элементарной ячейке. При этом 21 решеточное колебание распределяется по группам симметрии, т.е. в спектрах 
Химические и структурные формулы триптофана и тирозина

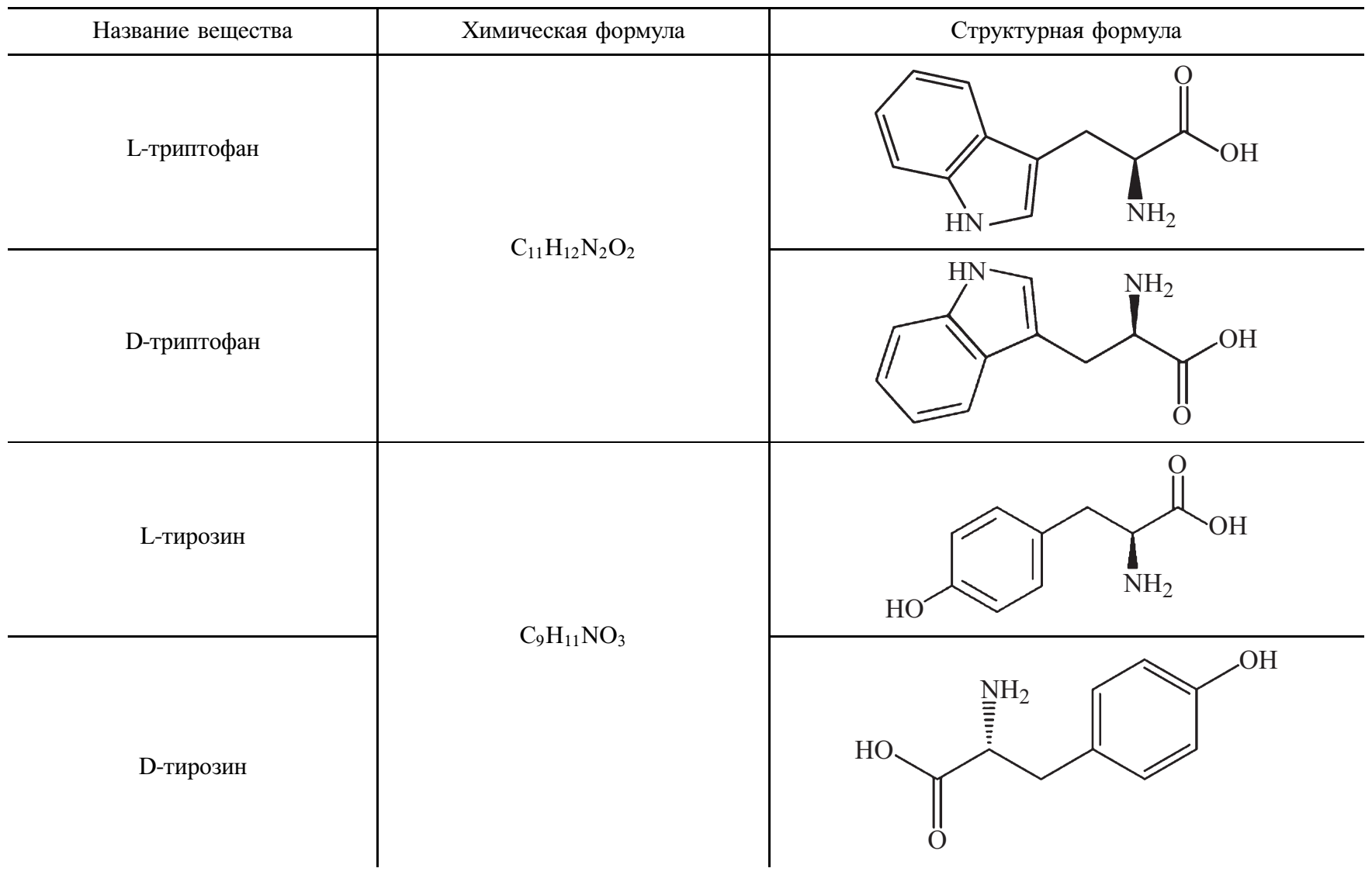

КР должно наблюдаться 12 колебаний, а в ИК поглощении - 9 колебаний кристаллической решетки триптофана. В спектре KP поликристаллов L- и D-триптофана наблюдается по 7 колебаний, а в рацемической смеси DL-триптофана 9 линий, среди которых имеются весьма интенсивные, особенно в низкочастотной области спектра. Вместе с тем интенсивность и полуширина межмолекулярных и внутримолекулярных мод изменяются от линии к линии. Аналогичная картина наблюдается для поликристаллических L- и D-тирозина, спектры КР которых приведены на рис. 3.

Существуют несколько способов сравнения спектров КР веществ: метод наименьших квадратов [34], метод функций корреляции спектров [35-38] и др. Остановимся на описании способа, основанного на построении разностных спектров, задаваемых с помощью распределения интенсивности спектра в нормированном цифровом виде. При этом рассчитываются разностные нормированные спектры рассеянного излучения [39-43] на основе следуюшего соотношения:

$$
K(v)=1-\left|I_{A}(v)-I_{E}(v)\right| .
$$

Здесь $I_{A}(v), I_{E}(v)$ - нормированные спектры рассеянного излучения анализируемого вещества $(A)$ и эталонного вещества $(E)$. Для анализа спектров КР используется так называемый коэффициент соответствия $K$ :

$$
K_{A}^{E}=\frac{\sum_{i=1}^{N}\left(1-\left|I_{A}(v)-I_{E}(v)\right|\right)_{i}}{N} .
$$

Здесь $N$ - число точек, для которых получены цифровые данные о спектре КР.

Для аналитического сравнения спектров KP L-, Dи DL-триптофана и L-, D-тирозина были построены разностные функции с использованием соотношения (1). Соответствующие спектры приведены на рис. 4, $a-d$. Разностные спектры строились в диапазоне частот $0-200 \mathrm{~cm}^{-1}$ с интервалом разбиения $\Delta v=0.25 \mathrm{~cm}^{-1}$. Кроме того, на основе соотношения (2) были вычислены соответствующие коэффициенты соответствия, которые приведены в подписях к рис. 4, $a-d$.

Как видно из рис. $4, a-d$, разностные спектры и коэффициенты соответствия позволяют установить степень сходства между различными модификациями аминокислот триптофана и тирозина. Следует отметить, что так как спектры KP L- и D-триптофана мало отличается друг от друга (рис. 4, $a$ и 4, $b$ ), то коэффициент соответствия $K_{D}^{L}=0.94$, т.е. ближе к единице по сравнению со спектрами KP L- и DL-триптофана (рис. 4, $a$ и 4,c), где коэффициент соответствия $K_{D L}^{L}=0.89$, а коэффициент соответствия D- и DL-триптофана $K_{D L}^{D}=0.90$. При 

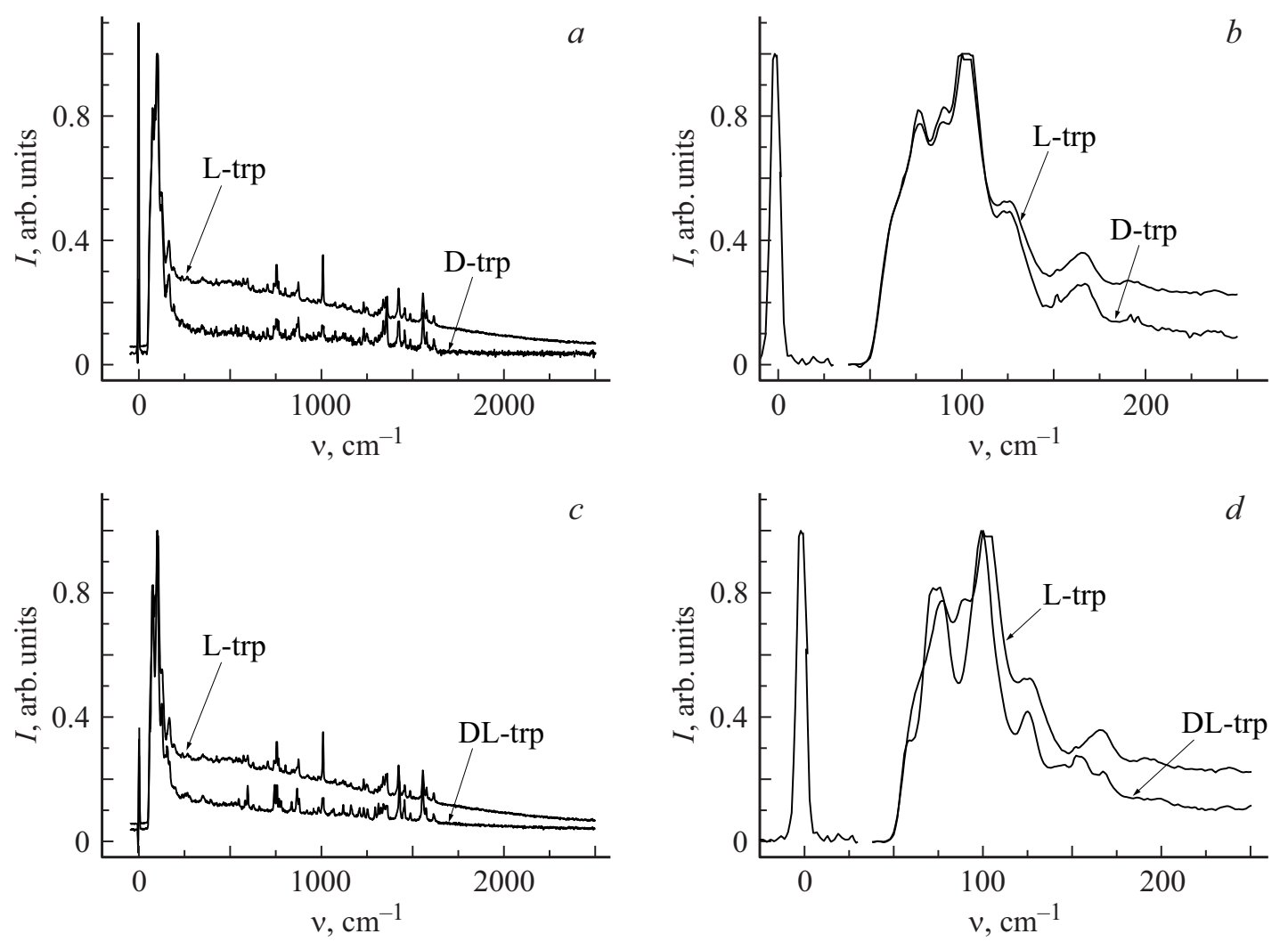

Pис. 2. Сравнение спектров KP L- и D-триптофана $(a, b)$, L- и DL-триптофана $(c, d)$, зарегистрированных в диапазонах частот $0-2700(a, c)$ и $0-250 \mathrm{~cm}^{-1}(b, d)$.
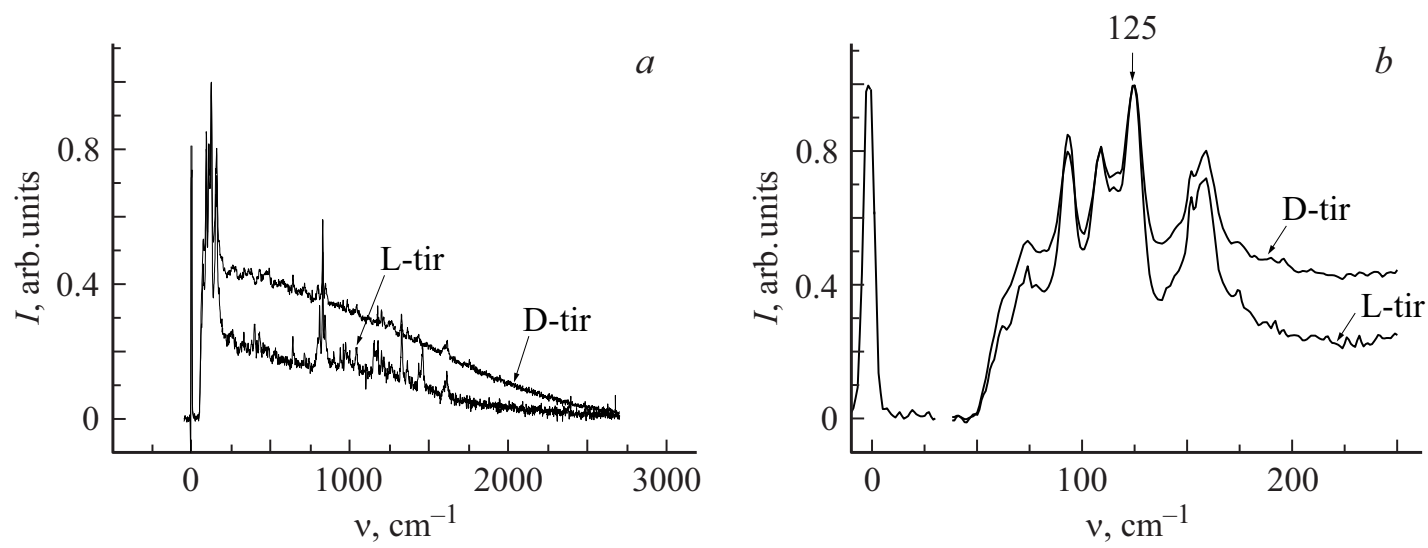

Рис. 3. Сравнение спектров КP L- и D-тирозина, зарегистрированных в диапазоне частот $0-2700(a)$ и $0-250 \mathrm{~cm}^{-1}(b)$.

сравнении спектров KP D- и L-тирозина коэффициент соответствия $K_{L}^{D}=0.90$ (рис. $4, d$ ).

При совпадении спектров КР анализируемых объектов коэффициент соответствия должен равняться единице. Отметим, что, как видно из рис. $2, a, 2, b$ и 3 , наблюдается отличие спектров КР L- и D-триптофана и L- и D-тирозина, т.е. правой и левой форм изучаемых аминокислот, аналогичная картина наблюдалась в спектрах фотолюминесценции (ФЛ) триптофана [27]. Нарушение закона зеркальной симметрии в спектрах левой и правой форм представляет принципиальный интерес [44]. На- дежное установление такой закономерности требует дополнительных исследований. Более простое объяснение наблюдаемых отличий в спектрах КР и ФЛ исследованных образцов D- и L-триптофана и тирозина состоит в возможности присутствия в них небольшого количества рацемата. Таким образом, на основе анализа спектров КР и ФЛ поликристаллических ароматических аминокислот может быть установлена степень их хиральной чистоты на количественном уровне.

Наблюдаемое отличие спектров КР и ФЛ хирально чистых фаз от рацемата можно объяснить тем, 

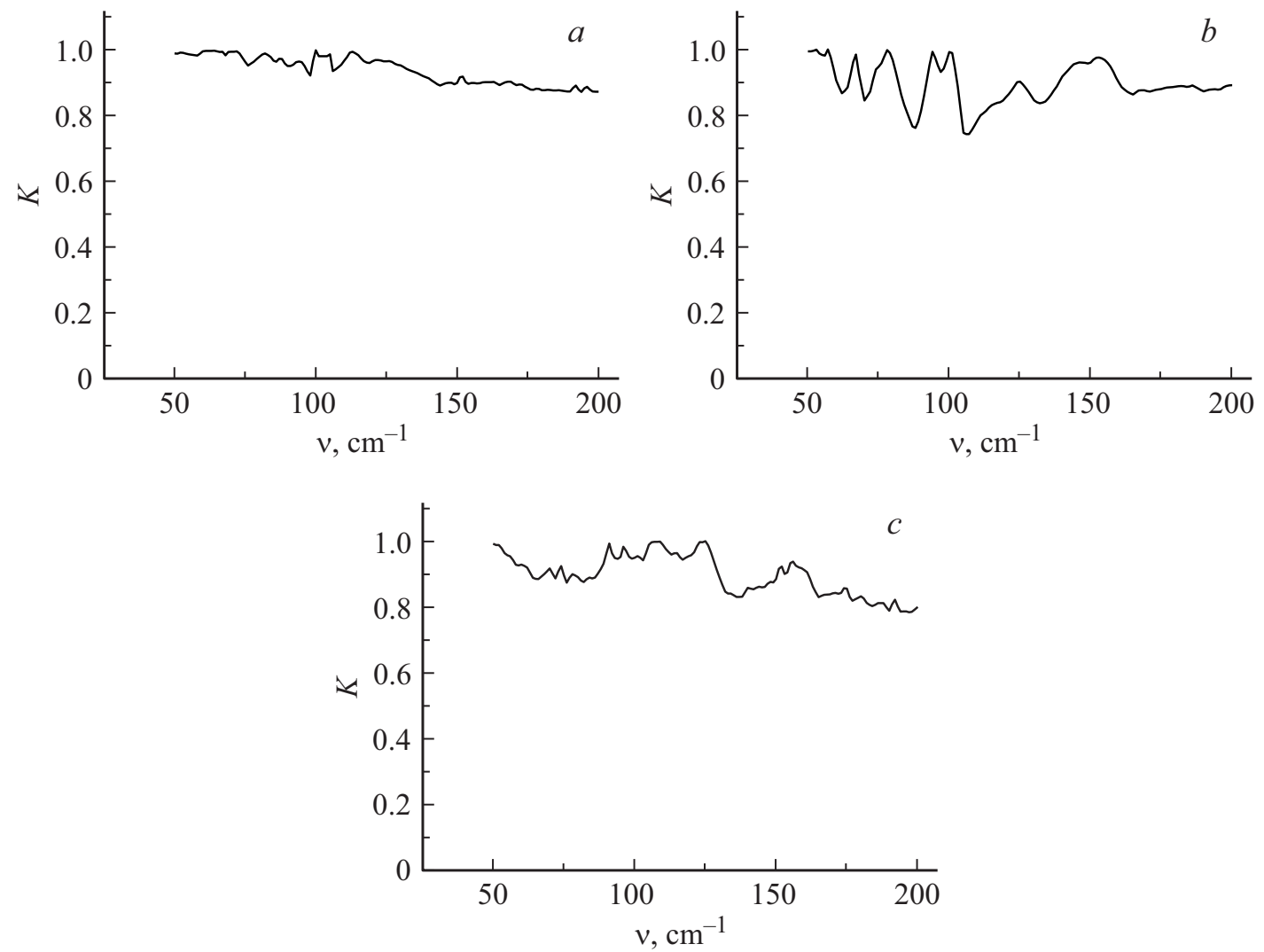

Рис. 4. Разностные спектры $K(v)$ в диапазоне $0-200 \mathrm{~cm}^{-1}: a-\mathrm{D}$-триптофан при сравнении с L-триптофаном, коэффициент соответствия $K_{D}^{L}=0.94 ; b-\mathrm{DL}$-триптофан при сравнении с L-триптофаном, коэффициент соответствия $K_{D L}^{L}=0.89 ; c-\mathrm{D}$-тирозин при сравнении с L-тирозином, коэффициент соответствия $K_{D}^{L}=0.90$.

что центросимметричная кристаллическая структура DL-триптофана существенным образом отличается от нецентросимметричной кристаллической структуры Dи L-триптофана. Молекулярное взаимодействие между зеркально симметричными молекулами в рацемической фазе приводит к изменению вида соответствующих электронных спектров. Это может быть причиной наблюдаемых в спектрах КР и ФЛ сдвигов положений максимумов и уширений полос.

С другой стороны, наблюдаемое различие в спектрах хирально чистых фаз и рацемата может быть использовано для анализа хиральной чистоты промышленных препаратов, широко используемых в настоящее время для ускорения роста биомассы животных. Присутствие в пище правых изомеров триптофана или тирозина, а также рацематов, входящих в состав белков и биологически активных сред, может приводить к патологии потребителей таких продуктов.

\section{Заключение}

Таким образом, в настоящей работе на примере ароматических аминокислот триптофана и тирозина установлено отличие спектров КР хирально чистых фаз ароматических аминокислот тритофана от соответствующей рацемической фазы этой аминокислоты. Кроме того, обнаружено отличие в спектрах КР „левых“ и „правых“ фаз триптофана, а также тирозина. Нарушение закона зеркальной симметрии в спектрах КР левой и правой форм аминокислот представляет принципиальный интерес. Возможно, наблюдаемые различия в спектрах КР левой и правой форм триптофана и тирозина связаны с особенностями их приготовления и присутствия в них различных примесей, возникающих в процессе роста поликристаллов. Разработанная методика волоконнооптической регистрации спектров КР обеспечивает получение экспресс-информации от небольшого количества анализируемой пробы с высоким пространственным разрешением по поверхности образца $0.1 \mathrm{~mm}$ при времени экспозиции, равном 10-100 s.

Известно, что при добавлении в комбикорм аминокислот триптофана и тирозина происходит набор мышечной массы у скота и птиц, а также накопление этих аминокислот в организме животных. Потребление при этом правой или рацемической форм триптофана или тирозина может привести к патологиям в организме и нарушению процессов метаболизма у животных, а также во всей цепочке организмов, в которые попадают правые или рацемические фазы аминокислот. Предлагаемый метод спектрального анализа хиральных фазовых 
состояний протеиногенных аминокислот может быть полезен для установления хиральной чистоты биологически активных веществ.

\section{Финансирование работы}

Исследование выполнено за счет гранта Российского научного фонда (проект № 19-12-00242).

\section{Конфликт интересов}

Авторы заявляют, что у них нет конфликта интересов.

\section{Список литературы}

[1] Breen M.S., Kemena C., Vlasov P.K. et al. // Nature. 2012. V. 490 . P. 535.

[2] Casado J., Lopez Navarrete J.T., Ramirez F.J. // J. Raman Spectrosc. 1995. V. 26. P. 1003.

[3] Jarmelo S., Reva I., Carey P.R. etal. // Vibr. Spectrosc. 2007. V. 43. P. 395.

[4] Moovendaran K., Martin Britto Dhas S.A., Natarajan S. // Spectrochim. Acta. A. 2013. V. 112. P. 326.

[5] Chuang C.-H., Chen Y.-T. // J. Raman Spectrosc. 2008. V. 40. P. 150.

[6] Kim S.K., Kim M.S., Suh S.W. // J. Raman. Spectrosc. 1987. V. 18. P. 171.

[7] Lee H.I., Suh S.W., Kim M.S. // J. Raman. Spectrosc. 1988. V. 19. P. 491.

[8] Dovbeshko G., Berezhinsky L. // J. Mol. Struct. 1998. V. 450. P. 121.

[9] Silva B.L., Freire P.T.C., Melo F.E.A. etal. // Braz. J. Phys. 1998. V. 28. P. 19.

[10] Lima J.A.Jr., Freire P.T.C., Lima R.J.C. etal. // J. Raman. Spectrosc. 2005. V. 36. P. 1076.

[11] Zhu G., Zhu X., Fan Q. etal. // Spectrochim. Acta. A. 2011. V. 78. P. 1187.

[12] Yao G., Zhang J., Huang Q. // Spectrochim. Acta. A. 2015. V. 151. P. 111.

[13] Silva J.A.F., Freire P.T.C., Lima J.A.Jr. etal. // Vibr. Spectrosc. 2015. V. 77. P. 35.

[14] Daniel A., Prakasarao A., Dornadula K. et al. // Spectrochim. Acta A. 2016. V. 152. P. 58.

[15] Белянчиков М.А., Горелик В.С., Горшунов Б.П., Пятышев А.Ю. // Кристаллография. 2017. Т. 62. № 2. C. 278; Belyanchikov M.A., Gorshunov B.P., Gorelik V.S., Pyatyshev A.Y. // Crystallography Reports. 2017. V. 62. N 2. P. 290.

[16] Suzuki S., Ohshima T., Tamiya N. et al. // Spectrochim. Acta. 1959. V. 15. P. 969.

[17] Dupuy B., Castinel C., Garrigou-Lagrange C. // Spectrochim. Acta A. 1969. V. 25. P. 571.

[18] Tipping M., Viras K., King T.A. // Biopolymers. 1984. V. 23. P. 2891.

[19] Jenkins A.L., Larsen R.A., Williams T.B. // Spectrochim. Acta. A. 2005. V. 61. P. 1585.

[20] Gaillard T., Trivella A., Stote R.H. etal. // Spectrochim. Acta. A. 2015. V. 150. P. 301.

[21] Casado J., Lopez Navarrete J.T., Ramirez F.J. // J. Raman Spectrosc. 1995. V. 26. P. 1003.
[22] Jarmelo S., Reva I., Carey P.R. etal. // Vibr. Spectrosc. 2007. V. 43. P. 395.

[23] Moovendaran K., Martin Britto Dhas S.A., Natarajan S. // Spectrochim. Acta. A. 2013. V. 112. P. 326.

[24] Gorelik V.S., Rakhmatullaev I.A. // Inorganic Mater. 2004. V. 40. N 7. P. 686

[25] Downesand A., Elfick A. // J. Sensors. 2010. V. 10. N 3. P. 1871.

[26] Sikirzhytski V., Virkler K., Lednev I.K. // J. Sensors. 2010. V. 10. N 4. P. 2869.

[27] Горелик В.С., Умаров М.Ф. // Опт. и спектр. 2018. Т. 125. № 1. C. 137; Gorelik V.S., Umarov M.F. // Opt. Spectrosc. 2018. T. 125. N 1. P. 144.

[28] Войнов Ю.П., Горелик В.С., Умаров М.Ф., Морозова С.В. // Краткие сообщения по физике ФИАН. 2011. T. 38. № 11. C. 13; Voinov Y.P., Gorelik V.S., Umarov M.F., Morozova S.V. // Bulletin of the Lebedev Physics Institute. 2011. V. 38. N 11. P. 328.

[29] Войнов Ю.П., Горелик В.С., Пятышев А.Ю., Умаров М.Ф. // Краткие сообщения по физике ФИАН. 2012. T. 39. № 12. C. 28; Voinov Y.P., Gorelik V.S., Pyatyshev A.Y., Umarov M.F. // Bulletin of the Lebedev Physics Institute. 2012. V. 39. N 12. P. 341.

[30] Горелик В.С., Литвинова Ф.О., Умаров М.Ф. // Краткие сообщения по физике ФИАН. 2014. Т. 41. № 11. С. 3; Gorelik V.S., Litvinova A.O., Umarov M.F. // Bulletin of the Lebedev Physics Institute. 2014. V. 41. N 11. P. 305.

[31] Умаров М.Ф., Горелик В.С. Оптическая спектроскопия биоактивных препаратов. Вологда: ВоГУ, 2014. 147 с.

[32] Войнов Ю.П., Горелик В.С., Умаров М.Ф., Юрин М.Е. Патент РФ № 2488097, 2013.

[33] Bakke O., Mostad A. // Acta Chemica Scand. 1980. B 34. P. 559.

[34] Глаголев К.В., Голяк И.С., Голяк И.С., Есаков А.А., Корниенко В.Н., Кочиков И.В., Морозов А.Н., Светличный С.И., Табалин С.Е. // Опт. и спектр. 2011. Т. 110. № 3. C. 486; Glagolev K.V., Golyak Ig.S., Golyak Il.S., Esakov A.A., Kornienko V.N., Morozov A.N., Tabalin S.E., Kochikov I.V., Svetlichnyi S.I. // Opt. Spectrosc. 2011. V. 110. N 3. P. 449.

[35] Глаголев К.В., Морозов А.Н., Назаренко Б.П., Табалин С.Е., Чубурков О.В., Светличный С.И., Никитаев С.П., Рожнов А.В., Филиппов В.И., Григорьев А.А. // Вестник МГТУ им. Н.Э. Баумана, серия „Естественные науки“. 2005. № 3. С. 9.

[36] Бойко А.Ю., Григорьев А.А., Мацюк Г.В., Павлов А.Ю., Шлыгин П.Е., Дворук С.К., Лельков М.В., Морозов А.Н., Табалин С.Е., Шишкин Г.В., Корниенко В.Н., Кочиков И.В., Светличный С.И. // Вестник МГТУ им. Н.Э. Баумана, серия „Естественные науки“. 2004. № 1. С. 26.

[37] Дворук С.К., Корниенко В.Н., Кочиков И.В., Лельков М.В., Морозов А.Н., Светличный С.И., Табалин С.Е. // Оптический журнал. 2004. Т. 71. № 5. С. 7.

[38] Морозов А.Н., Светличный С.И., Фуфурин И.Л. // Вестник МГТУ им. Н.Э. Баумана, серия „Естественные науки“. 2007. № 2. C. 3.

[39] Duguid J.G., Bloomfield V.A., Benevides J.M., Thomas G.J. // Biophysical. J. 1996. V. 71. N 6. P. 3350.

[40] Langlais M., Tajmir - Riahi H.A., Savoie R. // Biopolymers. 1990. V. 30. N 7. P. 743.

[41] Kint S., Tomimatsu Y. // Biopolymers. 1979. V. 18. N 5. P. 1073. 
[42] Benevides J.M., Overman S.A., Thomas G.J. // J. Raman Spectrosc. 2005. V. 36. N 4. P. 279.

[43] Бортников К.С., Горелик В.С., Есаков А.A // Неорганические материалы. 2007. Т. 43. № 12. С. 1458; Bortnikov K.S., Gorelik V.S., Esakov A.A. // Inorganic Materials. 2007. T. 43. N 12. C. 1313.

[44] Хриплович И.Б. Несохранение четности в атомных явлениях. М.: Наука, 1988. 288 с. 